\title{
Del $A b$ urbe condita de Tito Livio al Scipió e Anibal de Antoni Canals
}

Isaac Lampurlanés

Universitat de Lleida

\section{Introducción}

En el presente artículo pretendemos observar, principalmente, la translatio del poema épico Africa de Petrarca a la obra de Antoni Canals, Scipió e Anibal, enmarcado dentro de la prosa catalana de finales del XIV-principios del XV, época dorada para las letras valencianas ${ }^{1}$. Por otro lado, y en primer lugar, nos pareció oportuno ver el recorrido de la presencia y figura de la obra de Tito Livio desde la tardoantigüedad, pasando por su recepción en la Edad Media hasta llegar al Renacimiento donde retomará vigor. Primero sería "descubierto" por el prehumanismo de Lovato Lovati y finalmente por la refundición de Petrarca (el conocido códice harleyano) y la influencia del historiógrafo paduano en el Renacentista que le haría componer su poema épico, a imagen de una Eneida nacionalista, Africa, que nos llevará hasta Canals, con su traducción libre del Scipió e Anibal, donde nos expone los cambios de la fortuna, muy influenciado por la prosa de Bernat Metge ${ }^{3}$.

\footnotetext{
${ }^{1}$ Germà Colón Domènech (ed.), Els escriptors valencians del segle XV, Publicacions de la Universitat Jaume I, Castellón de la Plana, 2013.

${ }^{2}$ Giuseppe Billanovich, La tradizione del testo di Livio e le origini dell'umanesimo, Editrice Antenore, Padua, 1981, pp. 1-33, especialmente pp. 1-6.

${ }^{3}$ Martí de Riquer, Antoni Comas, Joaquim Molas, Història de la literatura catalana, Editorial Ariel, Barcelona, 1984, vol. III, pp. 129-131.
} 
Antes de nada y para ceñir aún más nuestro campo de observación debemos mencionar que los libros de Tito Livio que aparecerán en dicho artículo como centro de atención será la que tradicionalmente se ha conocido como la tercera década, la que concierne a la Segunda Guerra Púnica ${ }^{4}$, pues tanto Africa como su translatio valenciana se centran en la confrontación entre Aníbal y Escipión, y de l'Africa nos centraremos sobre todo en el comentario del libro VII, ya que nos ceñimos a las correspondencias propuestas por Sanvisenti entre los dos autores ${ }^{5}$.

\section{Tito Livio y su $A b$ urbe condita}

Nuestro periplo hacia la traducción y la reinterpretación renacentista nos lleva imperiosamente al origen y composición de los ciento cuarenta y dos libros (de los cuales solo conservamos íntegros del 1 al 10 y del 21 al $45^{6}$ ) del Ab urbe condita, que narra la historia de Roma desde el 753 a. C. (año mítico de la fundación de la ciudad) hasta la muerte de Druso, hijo adoptivo de Augusto $^{7}$, escritos por el

nativo de Patavium (Padua), Tito Livio, que debemos enmarcarlo ${ }^{8}$ en la misma generación de Augusto y más joven que Virgilio.

Tito Livio supo ganarse la aceptación del pueblo romano y de la elite intelectual ya en vida $^{9}$ gracias a su prosa. Escribe una prosa que usa del período ${ }^{10}$ al estilo de Cicerón, ya que la historiografía es en sí mismo también un ejercicio de

\footnotetext{
${ }^{4}$ Michael von Albrecht, Historia de la literatura romana, trad. Dulce Estefanía, Andrés Pociña, Empresa Editorial Herder, Barcelona 1997, p. 773; Titus Livi, Història de Roma, Antoni Cobos (ed.), Fundació Bernat Metge, Barcelona, 2002, vol. I, p. 32.

${ }^{5}$ Bernardo Sanvisenti, I primi influssi di Dante del Petrarca e del Bocaccio sulla letteratura spagnuola, Hoepli, Milán, 1902, pp. 380-381.

${ }^{6}$ Michael von Albrecht, Historia de la literatura romana..., p. 773; Tito Livio, Historia de Roma desde su fundación. Libros I-III, José Antonio Villar Vidal (ed.), Editorial Gredos, Madrid, 1990, pp. 15-16; Titus Livi, Història de Roma..., vol. I, pp. 11-12.

${ }^{7}$ Titus Livi, Història de Roma..., vol. I, p. 10.

${ }^{8}$ Difícil de precisar un año exacto de nacimiento: Jerónimo lo hace nacer en el 59 a. C., aunque dice que también era coetáneo de M. Valerio Mesala, nacido el 64 a.C.; Michael von Albrecht, Historia de la literatura romana..., p. 771; Titus Livi, Història de Roma..., vol. I, p. 12.

${ }^{9}$ Titus Livi, Història de Roma..., vol. I, pp. 7-8.

${ }^{10}$ Jean Bayet, Literatura Latina, Editorial Ariel, Barcelona, 1975, pp. 259-260.
} 
la oratoria ${ }^{11}$, con ciertos rasgos de dramatismo ${ }^{12}$ que le daban intensidad a la narración, así como el desarrollo de una narración casi épica ${ }^{13}$, de un curso regular, ininterrumpido, en que las propias monotonías se armonizan con el tono general.

Esta fama casi inminente hizo que su obra fuera muy copiada ya en la antigüedad y tenemos por seguro que se conservó la "gran" obra íntegra hasta finales de ésta ${ }^{14}$. Más adelante, a causa de su gran envergadura, se hicieron epítomes y compendios más manejables (lo que se conoce como periochae) de la obra, cosa que pudo ser causa de la dispersión y de la pérdida de contenido ${ }^{15}$, aunque hasta el siglo V vemos que se copian fragmentos de Livio con asiduidad. En los siglos IX y XI, Livio es muy copiado como lo atestiguan los manuscritos conservados conocidos como el Puteanus (que contiene la tercera década) o los Fragmenta Piacentina, los Romana (de la cuarta década) o el códice Vindobonensis (que contiene la quinta década), que proviniendo de Italia, pero viajan bastante.

En época carolina y hasta el siglo XII es dudosa su presencia en las bibliotecas: puede que Eginardo lo conociera ${ }^{16}$, lo cita y lo busca Lupo de Ferrières i seguramente lo conoció Alcuino de York.

Hacia el siglo XII, parece que se copiaba el texto más que no leerse. Es entonces cuando encontramos las agrupaciones de los libros en bloques de cinco o diez libros (las décadas), ya que la misma estructura interna con sus prólogos (libros 6, 21 y 31) y su especialización temática, casi como monografías, parece aventurar que se pueda dividir de diez en diez, aunque el número total de libros no lo corro-

\footnotetext{
${ }^{11}$ Jesús Bartolomé Gómez, Los relatos bélicos en la obra de Tito Livio, (Estudio de la primera década de 'Ab urbe condita'), Universidad del País Vasco, Vitoria, 1995, pp. 17-24; Jean Bayet, Literatura Latina..., pp. 265-266.

12 Jean Bayet, Literatura Latina..., p. 260.

${ }^{13}$ Jean Bayet, Literatura Latina..., p. 262.

${ }^{14}$ Titus Livi, Història de Roma..., vol. I, p. 84.

${ }^{15}$ Michael von Albrecht, Historia de la literatura romana..., pp. 796-798.

${ }^{16}$ Hubert, Mordek, "Livius und Einhard - Gedanken über das Verhältnis der Karolinger zur antiken Literatur", Livius, Werk und Rezeption:Festschrift für Erich Burck zum 80. Geburtstag, Eckard Lefèvre, Eckart Oshausen (ed.), C.H. Beck, München, 1983, pp. 337-346.
} 
bora $^{17}$. En dicho siglo, ya vemos una utilización directa del texto como Lambert de Hersfeld, que los utilizó para sus Annales o Juan de Salisbury. Ya en pleno siglo XII, en territorio italiano, Livio es leído e imitado en el conocido círculo de Padua $\left(\right.$ Lovato, Mussato ${ }^{18}$ ), desde donde quizás llegó a Chartres ${ }^{19}$. A partir de entonces, empezaron a haber diferentes ejemplares ya en el siglo XIV y desde Italia o de escribanos italianos se trasladaron a Aviñón ${ }^{20}$, donde se encontraría Petrarca.

\section{Petrarca}

\subsection{Petrarca 'philologus' y su relación con Tito Livio}

La primera etapa de la carrera de Petrarca es conocida por ser la del philologus incipiente, que buscaba la esencia clásica, grecolatina, como paradigma ideal y término permanente de comparación con el presente.

Es la época en que se esforzó en buscar los testimonios culturales de la Antigüedad, la palabra hecha ciencia. Su rechazo por el saber medieval, pues advirtió la inadecuación que suponía el contemplar la antigüedad a través de un prisma medievalista, la lógica escolástica, en favor del regreso de la palabra de los clásicos, en un intento de remodelar la importancia tradicional de los saberes, favoreciendo a la cultura literaria y la filosofía moral ${ }^{21}$. Logró más que nadie, más que sus predecesores los prehumanistas paduanos (Lovato o Mussato), revivir los ideales de la antigua Roma, incluso rivalizando con los clásicos en sus creaciones y desató pasiones y ambiciones por reanimar todo el legado cultural del mundo antiguo.

\footnotetext{
${ }^{17}$ El número total de libros es de 142, número que no es divisible por 10. Referente a las diferentes hipótesis sobre el tema: Titus Livi, Història de Roma..., vol. I, p. 10; También sobre la agrupación de los libros y discrepantes a las décadas: Titus Livi, Història de Roma..., vol. I, p. 32.

${ }^{18}$ Giuseppe Billanovich, La tradizione del testo di Livio..., pp. 1-33.

${ }^{19}$ Giuseppe Billanovich, La tradizione del testo di Livio..., pp. 123-175.

${ }^{20}$ Giuseppe Billanovich, La tradizione del testo di Livio..., pp. 41-56.

${ }^{21}$ Guido M. Cappelli, El humanismo italiano. Un capitulo de la cultura europea entre Petrarca y Valla, Alianza Editorial, Madrid, 2007, pp. 27-32.
} 
El traslado de la sede papal de Roma a Aviñón ${ }^{22}$ en el siglo XIV benefició a los intereses del joven Petrarca, pues cuando llegó allí se encontró con una generación anterior letrada con un interés activo. En la British Library se conserva el manuscrito de Livio (el Harley 2493, Lám. XV) que puede atestiguar esta importancia de Aviñón en el crucial puente establecido entre la Edad Media y el Renacimiento. Podemos decir, que este volumen, que contenía en origen los libros 1-10 y 21-40, fue recopilado por Petrarca.

Entre sus metas más hercúleas cabe destacar el reunir el mayor número posible de libros de Livio hasta la fecha conocidos, ya que a lo largo de la Edad Media todas las décadas se habían dispersado o extraviado. La elección de Livio no es baladí: Es la principal fuente sobre la Roma republicana, época crucial para entender el espíritu que acompaña el Humanismo. El resultado de su trabajo filológico fue único en Occidente hasta la fecha: aportó un importante aparato de notas, escolios y glosas y convirtió el manuscrito harleyano en la primera "edición crítica" europea.

El núcleo del libro es un manuscrito de la tercera década de Livio, copiado hacia 1200 y que provenía en último lugar del Puteanus. Petrarca le añadió alrededor del 1325 una copia de la primera década y años después, una de la cuarta. $\mathrm{Su}$ proceso fue laborioso y de viajes constantes porque primero tuvo que buscar en Italia, donde recogió los frutos del que había conseguido el nombrado círculo de Padua de Lovato y de Mussato, después en Aviñón y en París ${ }^{23}$. Contándolo todo, agrupó las décadas primera, tercera y cuarta, a excepción del libro XXXIII y el final del XL, consiguiendo en 1329 ya el Livio más completo y el mejor texto que cualquiera otro de los existentes.

Su labor con Livio fue tal que hasta se inspiró en él para su epopeya latina Africa y le escribió una carta a Livio, tal como hizo con otros clásicos antiguos, en la cual ponderaba sus propios esfuerzos para reunir los trozos de su obra. $\mathrm{Su}$ periplo empezó cuando en 1328 Landolfo Colonna, de cuyo patronazgo se benefició Petrarca y que fue canónigo de Chartres, llevó a Aviñón un antiguo manus-

\footnotetext{
${ }^{22}$ Leighton D. Reynolds, Nigel G. Wilson, Copistas y filólogos [Scribes and Scholars], trad. Manuel Sánchez, Editorial Gredos, Madrid, 1995 [1 ${ }^{\mathrm{a}}$ original 1968], pp. 126-130.

${ }^{23}$ Titus Livi, Història de Roma..., vol. I, p. 86.
} 
crito de Livio que había hallado en la catedral de Chartres ${ }^{24}$ : el Vetus Carnotensis, pariente cercano del perdido Spirensis, y ambos derivan, en cuanto a la cuarta década, del manuscrito uncial del siglo V que Otón III encontró en Piacenza y se llevó a Alemania ${ }^{25}$. El gran manuscrito de Livio que al final "editó" Petrarca, será luego el que tendrá Lorenzo Valla, cuyas famosas correcciones pueden verse en los márgenes ${ }^{26}$ Despertó el interés de quien sería el primer traductor de Livio al francés, cuya obra se ha conservado, Pierre Bersuire, que dedicó su obra al rey francés Juan el Bueno. Bersuire había convivido con Petrarca durante diversos meses en París.

Petrarca introdujo Livio entre los autores latinos que, en el siglo XIV, se iban reproduciendo habitualmente en Aviñón, generando una irradiación de copias de Livio que se extendería en todas direcciones por Europa i daría pie a un gran número de manuscritos que aún hoy existen. Esta rápida presencia de Livio en las bibliotecas a finales de los siglos XIV y XV traería como consecuencia la lectura, la imitación y la influencia del historiador en la cultura literaria y política de la época. Así pues, desde Petrarca ya se podían leer y reproducir por toda Europa veintinueve libros casi enteros (mientras que por ejemplo Dante solo conoció la primera década).

Ciertamente, las obras de esta primera fase de philologus, como el Africa o el De viris illustribus, responden a un afán de "clasicismo por el clasicismo" y pretenden hacer un alarde de erudición que había caído en el olvido. Pero también podemos percibir esa nueva aura ideológica que tiene el humanismo, con su intención de utilizar el clasicismo como vehículo de transporte de nuevas ideas y modelos ejemplares que derivan de la conciliación de los clásicos (ya menospreciados por la acaparadora teología cristiana) y el cristianismo. Rápidamente este espíritu renacentista y renovador de la mentalidad del hombre medieval y de sus gustos caló en una nueva generación, empezando por el joven contemporáneo de Petrarca Bocaccio (1313-1375).

${ }^{24}$ Sobre la biblioteca de Chartres: Giuseppe Billanovich, La tradizione del testo di Livio..., pp. 123-175.

${ }^{25}$ Leighton D. Reynolds, Nigel G. Wilson, Copistas y filólogos..., p. 107.

${ }^{26}$ Leighton D. Reynolds, Nigel G. Wilson, Copistas y filólogos... p. 139 


\subsection{Africa: obra y tema}

La obra Africa es un poema épico que reúne nueve libros con un total de 6800 versos que intenta emular, aunque también equipararse, a la obra de Virgilio, la $E_{n e i d a^{27}}$. Su relación con la épica latina virgiliana no termina ahí, pues la obra permaneció inacabada y vio la luz tras la muerte del autor. Desde 1377 Coluccio Salutati disponía de un manuscrito de la misma y la publicó en 1396 en una reunión de amigos poetas.

El objetivo de esta colosal e inacabada obra fue la equiparación y lid con los poetas antiguos. Petrarca quería ser el Homero y/o Virgilio de su tiempo y para ello debía superarlos en su mismo terreno: la épica y el metro hexámetro, el cual representaba una innovación en aquella época. Irónicamente también el humanista pecará de los mismos desvíos que el modelo de Mantua y al ver inacabada la obra, para evitar que otra mano la corrigiese, se plantea quemar su obra como expresa en el Secretum: ignibus eam propriis manibus mandare decreueram.

Vemos en esta obra la conciliación entre el mundo pagano (representado por el lenguaje y el tema) y el cristianismo, motivo que intentaron pergeñar los humanistas después de Petrarca. En esta línea de conciliación, vemos atributos de este nuevo Eneas, el elogiado Escipión, como el de pius y que contiene las virtudes de constantia, modestia, humanitas y amicitia que se adaptan a la nueva óptica cristiana contemporánea del autor ${ }^{28}$. También es posible ver en la misma obra un carácter político. Petrarca ya pregonaba un incipiente nacionalismo italiano perceptible en primer lugar en el personaje: el romano virtuoso que lucha por su patria y que se encuentra en África, título de la obra, territorio que queda enfrente de Italia. Región ante región, una realidad ante otra, religión contra religión, quizás rememorando los versos de la agonizante Dido que vaticinaba el odio de los romanos y cartagineses,

Litora litoribus contraria, fluctibus undas imprecor, arma armis; pugnent ipsique nepotesque. ${ }^{29}$

\footnotetext{
${ }^{27}$ Francesco Petrarca, Africa..., p. 5.

${ }^{28}$ Francesco Petrarca, Africa..., p. 26.

${ }^{29}$ Virgilio, Eneida, IV, vv. 628-629
} 
Dos ciudades que dominaban un territorio y que quedaban una delante de la otra, desafiantes. Roma ante Cartago, o más ampliamente, Italia ante África. Se define así Italia por contraste con África.

La obra bebe en cuanto a discurso narrativo y hechos expresos de las fuentes de Tito Livio, que, como hemos apuntado, el autor conocía y había estudiado bien y del que el autor se permite el versificar extractos enteros. Los hechos narrados se sitúan en los últimos años de la segunda Guerra Púnica, un período que puso a prueba la joven república romana sobre el panorama mediterráneo. En este escenario es puesto como protagonista a un joven Escipión, quien después se le conocería como el Africano. En el relato medieval se nos dibuja un Escipión símbolo del bien y del buen cristiano que lucha contra el Mal, Hannibal, un diestro estratega que hasta entonces no había tenido rival en batalla. El joven Escipión, héroe aquí épico y salvador de Roma es desde entonces agraciado por la fortuna, paganización de la providencia, y balancea a favor de los romanos el destino de la guerra.

Sucintamente, la acción de la obra se abre con una invocación de las Musas y de Crista (conciliación susodicha) y la presentación de las dos ciudades rivales y del héroe Escipión que llevó la guerra sobre suelo africano. Le sigue un sueño que tiene Escipión en el que aparece su padre revelándole el devenir de los acontecimientos futuros. A continuación tiene lugar la embajada de Lelio en Sífax, dando pie a Petrarca para recitar la grandeza de Roma y sus victorias. Se cambia de escenario a África, donde Escipión toma Cirta, capital de Sífax gracias a su aliado númida Masinisa. Llega al fin la batalla decisiva, precedida de un inventario de las fuerzas presentes (como en el libro II de la Ilíada). Después de la victoria de Zama, la escena se traslada a Roma con la embajada cartaginesa que negocia la paz y a la que se exige y reprende duramente. En el último libro, llevando a cabo el regreso a casa, el poeta Enio, amigo de Escipión, le explica el sueño que ha tenido: Homero en persona se le aparece y le revela el porvenir de la poesía y en particular la llegada de Petrarca, poeta que cantará las glorias de Roma ${ }^{30}$. Al final se exhibe la escena de los dos entrando triunfantes en Roma ${ }^{31}$.

\footnotetext{
${ }^{30}$ Recuerda a las palabras proféticas de Anquises a su hijo en Virgilio, Eneida, VI, 789-796.

${ }^{31}$ Francesco Petrarca, Africa..., p. 7.
} 


\section{Antoni Canals: vida y obras de traducción}

En el humanismo de las letras catalanas, junto al barcelonés Bernat Metge, suele tener un lugar distinguido la figura de Antoni Canals. Si bien Metge con su gusto por los clásicos hacía eco de un escepticismo filtrado en la evocación de los autores antiguos, Canals y su contemporáneo Francesc Eiximenis, conscientes de la crisis del cristianismo que había impulsado la paganización del lenguaje y el escepticismo, lo combaten con las mismas armas literarias enfocadas en los autores clásicos ${ }^{32}$.

\subsection{Sucintos apuntes biográficos}

Nació nuestro autor en Valencia el 1352. Ya de bien pequeño debió entrar en la orden de los dominicos y emprendió sus estudios de gramática en 1369 en Valencia y el año siguiente en Girona. En 1371 inicia a estudiar lógica y continua en Manresa y Lleida, el 1372 y 1373 respectivamente. En 1375 estudiaría filosofía en el monasterio de Barcelona bajo el cuidado de Vicent Ferrer y dos años más tarde será nombrado lector de lógica en el estudio general dominico de Barcelona. En 1378 sabemos que estudió teología en el convento de Valencia. Fue un estudiante ejemplar y muy ducho, tal como lo demuestra el que fuera transferido a Tolosa y puede que también a París. También son reveladoras sobre su virtud intelectual las palabras halagadoras que transmite el rey Juan I el 1391 a los dominicos de Valencia. En esta carta ya se muestran sus cualidades como traductor, pues el rey Juan I dice: que $\cdot n$ s exponga e reduesca de lati en nostre vulgar alscuns libres, los quals nós, qui·ns delitam molt en ligir, poguéssem sens gran dificultat e studi entendre.

En octubre de 1395 tomó la cátedra de teología de la catedral de Valencia y en 1398 y 1399 se pone al servicio de la capellanía real en la corte de Martín I. Entre los años 1399 y 1400 tuvo cierta tensión con el poder, tanto local, cuando en 1399 los jurados de Valencia amonestan la actitud insolente del fraile hacia los regidores de Valencia, como real cuando en 1401 el rey Martín I pone de manifiesto el descuido en cuantos a los herejes, siendo éste lloctinent de l'inquisidor general del regne de València.

\footnotetext{
${ }^{32}$ Martí de Riquer, Antoni Comas, Joaquim Molas, Història de la literatura catalana...., vol. III, pp. 107-110.
} 
El 1403 Antoni Canals fue nombrado predicador general junto a su hermano Pere Canals. Diez años más tarde vemos que la realeza, en este caso Violant de Bar, viuda de Juan I, se interesa por Canals para que redacte un Tractat de confessió, producción propia en catalán, y seguramente también una traducción de los Evangelios que al final no realizó.

\subsection{Traducciones y estilo}

Antoni Canals, en cuanto atañe a este artículo, fue traductor de obras de matiz clasicista como Scipió e Anibal, la obra de Valerio Máximo Dictorum factorumque memorabilium o el De providència de Sèneca.

Su obra que emprendió con más ímpetu fue el Dictorum factorumque memorabilium de Valerio y de la cual podemos dilucidar algunos aspectos de su método y estilo. No se la puede, asimismo, considerar una obra hija del fervor filológico humanista, ya que tal como afirma él (jatsesia [encara] que l'hagen tret en lengua catalana) es una obra ya traducida y conocida en el reino de Aragón. Incluso su contemporáneo Francesc de Eiximenis cita al autor latino. No obstante, en esta obra podemos ver la desenvoltura de su traducción: es clara, elegante y fácil, aunque su educación sumamente escolástica le haga cometer ciertas confusiones y errores derivados del desconocimiento del latín clásico. Asimismo, su conocimiento y afición de los autores clásicos, que se permite el intercalar pasajes extraídos de Tito Livio, lo convierten en un humanista ${ }^{33}$.

Se puede observar en ésta y en la obra que comentaremos, Scipió e Anibal, una faceta moralista que tiende al pesimismo al describirnos un mundo (el suyo) falto de virtudes y que en Roma, aun no conociendo todavía las virtuts teologals, las gentes actuaban con pleno respecto a la moral, es decir, amor al bien público, respeto a Dios y acción justo y recto, topos que encontraremos también en la traducción del Africa ${ }^{34}$. Su actitud de moralista, asimismo, se deja entrever en los autores en los que tiene interés: Valerio Máximo, Tito Livio, Séneca... Es decir,

\footnotetext{
${ }^{33}$ Martí de Riquer, Antoni Comas, Joaquim Molas, Història de la literatura catalana...., vol. III, p. 122.

${ }^{34}$ Martí de Riquer, Antoni Comas, Joaquim Molas, Història de la literatura catalana...., vol. III, p. 124.
} 
elige historiadores y filósofos que hablan de gentes del pasado, una época dorada, mejor, moralmente más pura y sana y eso es lo que el valenciano quiere transmitir. Evidentemente un gusto por las letras y el estilo clasicista tuvo, pero no fue el motor principal, ya que se desprende, por ejemplo en el Scipió e Anibal, del artificioso verso hexámetro del Africa para escribir más prosaicamente.

\section{Scipió e Anibal}

Esta obra la escribió Canals dirigido a Alfonso, duque de Gandía, tal como expresa en el prólogo: Al molt alt senyor lo senyor don Alfonso, duch de Gandia ${ }^{35}$. Esta referencia nos ocasiona un problema en la datación de la obra, pues el fraile pudo haber conocido a dos Alfonsos con dicho título: tanto puede ser Alfons I, conde de Denia y Ribagorza, intitulado duque de Gandia el año 1399 y muerto el 1412, como su hijo Alfonso II, muerto el 1422. Sabiendo que la obra tiene que ser posterior al De providència, ya que lo cita en el prólogo del libro (Creu jo que assò permet la sobirana Providència per mostrar a nós que no·ns devem apropriar açò qui no és nostra ${ }^{36}$ ), cabe situar esta obra entre el 1399 y el $1407^{37}$.

\subsection{Prólogo}

El prólogo puede considerarse dentro de la obra como una de las pocas partes de cosecha propia del autor valenciano, donde puede desenvolver su preocupación de moralista. En este nos ofrece información sobre sus fuentes, que comentaremos más extensamente más adelante, y sobre la "lectura" que debe hacerse de la misma desde una vertiente moral.

Nos indica Canals que se fijó y centró en la batalla que aparece y se desarrolla en el séptimo libro del África de Petrarca porque le movieron tres razones:

\footnotetext{
${ }^{35}$ Antoni Canals, Scipió e Aníbal. De Providència. De arra de ànima, ed. Martí de Riquer, Editorial Barcino, Barcelona, 1935, p. 31.

${ }^{36}$ Antoni Canals, Scipió e Aníbal..., p. 34.

${ }^{37}$ Martí de Riquer, Antoni Comas, Joaquim Molas, Història de la literatura catalana..., vol. III, p. 129.
} 
1. Mostrar lo voluble que llega a ser la fortuna pasajera.

2. Los resultados en la guerra son dudosos. Es decir, se pueden ganar batallas y luego perder la guerra.

3. Demostrar la desgracia del destino del guerrero.

Todo ello está dedicado, podemos deducir, al personaje de Aníbal, quien disfrutaba de una fortuna casi inagotable hasta que se presenta Escipión; Aníbal gana las batallas pero pierde la guerra y por último, siendo un buen guerrero, Aníbal cae en desgracia. Todo ello puede ser atribuido por el hecho de que éste representa al musulmán, cegado en una fe equivocada, aun con potencial, en contraste con Escipión, también ser destacado, pero sobre todo cristiano, quien sobresale y vence.

También, por su faceta moralista y el uso para dicho fin que se extrae de filósofos e historiadores, no duda en citar a su ya conocido Valerio

segons que diu Valeri, tota la cavaleria del cel havia singularment armat contra los romans, dels quals féu tan gran destrucció, en la batayla que s donà en Cannes, que pozà Roma a periyll de ésser despoblada, aprés de les grans astúcies de què usà molt arterozament. ${ }^{38}$

E per ço diu Valeri en lo VI libra, en lo títol "De mutació de fortuna", que molt són alanegables e frèvols los béns de fortuna, e son fetz semblants a les calçes dels minyons, de les quals no sap hom de quin peu són.

o también a Séneca cuando habla de la fluidez y vaivén de la fortuna y como esta se pone al servicio de Dios y no es el mismo Dios (referencia también a Boecio): E com Aníbal se fías massa en les victòries que avia obtengudes, a la fin se trobà enganat per la fortuna voluble, instable e constant.

No da un juicio sobre el porqué explícitamente Aníbal pierde la guerra, pero Canals da unas directrices que deben seguirse para salir victorioso:

${ }^{38}$ Antoni Canals, Scipió e Aníbal..., p. 32. 
1. El príncipe debe lo mejor para el estado.

2. Luchar por lo justo: castigar las injurias.

3. Luchar por el bien y no por codicia.

4. Luchar sin presumir. Demostrar humildad.

5. Ir a la batalla libre de pecados.

Al indicarnos los caminos del éxito y exponiendo que Aníbal ha sido derrotado, se nos presenta por omisión un Aníbal codicioso, injurioso, presuntuoso y pecador. Da una imagen de "musulmán" estereotipado que se contrapone al prototipo de cristiano virtuoso, en este caso Escipión: Cor, en una batayla se lig que són estatz vensadors los cristians, e en altra los imfezels ${ }^{39}$.

Además, se acentúa la pecaminosidad de Aníbal al suicidarse, aun habiendo obtenido tantos honores en diversas batallas, que está en relación con lo que exponía de la mala dicha del guerrero: Maraveyl-me fort de Aníbal, qui fo axi gloriós en armes com fou la fin tant miserable, matant si mateix ab verí, en la qual coza mostrà gran flaquesa de cor. ${ }^{40}$; Adonchs, com Aníbal, traent la sua ànima del cor ab cruel verí, no sia mort gloriosament, ans viciosa. ${ }^{41}$

\subsection{Fuentes}

En el prólogo nos informa que sus fuentes son tanto la obra de Petrarca como el historiador Tito Livio.

Per què, ligint de una part Tito Lívio, qui·l posà assatz largament, e d'altra Francesch Patrarcha, qui en lo seu libra appelat 'Affricha' trectà fort belament e diffusa, he aromansat lo dit parlament segons mon petit enginy.

\footnotetext{
${ }^{39}$ Antoni Canals, Scipió e Aníbal..., p. 37.

${ }^{40}$ Antoni Canals, Scipió e Aníbal..., p. 40.

${ }^{41}$ Antoni Canals, Scipió e Aníbal..., p. 41.
} 
No obstante, es grosso modo una traducción libre del libro VII de Petrarca, con la excepción del prólogo y el epílogo. Sabemos que Canals debía estar avezado a la lectura de Livio al incluir en su traducción de Valerio Máximo el episodio de Lucrecia que debió extraer de Livio, por tanto no le debía ser desconocido. Así pues teniendo las lecturas de Livio y Petrarca en la mayoría de casos se decantó por esta última. Para ilustrarlo, expondremos con unos ejemplos de extractos de los tres autores y veremos el camino del concreto episodio de la batalla entre Aníbal y Escipión desde Livio hasta Canals, pasando por Petrarca, quien "poetiza" los sucesos y los recogerá, a veces, de tal manera el valenciano.

\begin{tabular}{|l|l|l|}
\hline \multicolumn{1}{|c|}{ Tito Livio } & \multicolumn{1}{|c|}{ Petrarca } & \multicolumn{1}{c|}{ Antoni Canals } \\
\hline $\begin{array}{l}\text { Traditos eos tribuno } \\
\text { militum, iussosque } \\
\text { omisso metu visere om- } \\
\text { nia, per castra qua ve- }\end{array}$ & $\begin{array}{l}\text {... Tunc ille tribunis } \\
\text { Imperat ut circumductis per } \\
\text { llent circumduci iussit } \\
\text { (Liv., XXX, } 29)\end{array}$ & $\begin{array}{l}\text { E tantost manà lo dit Scipió } \\
\text { que no prenguessen dampnat- } \\
\text { ge, ans vol que.ls sia amostra- } \\
\text { da tota la host com és ordona- } \\
\text { Atque equitum peditumque ha- } \\
\text { bitus numerumque manusque/ } \\
\text { paretur... } \\
\text { palissades, les diversitatz de } \\
\text { les armes, les gentz a caval, } \\
\text { los hòmens a peu e lo nom- } \\
\text { bra dels combatents. } \\
\text { (Cap. I) }\end{array}$ \\
\hline
\end{tabular}

\begin{tabular}{|c|c|c|}
\hline Tito Livio & Petrarca & Antoni Canals \\
\hline $\begin{array}{l}\text { nam et Massinissam cum } \\
\text { sex milibus peditum quat- } \\
\text { tuor equitum venisse eo } \\
\text { ipso forte die adferebant } \\
\text { (Liv. XXX, 29) }\end{array}$ & $\begin{array}{l}\text { Talia dum Latius peragit } \\
\text { dux, forsitan illo/ } \\
\text { Massinissa die peditumque } \\
\text { equitumque caterve/ } \\
\text { Ingentes alacri veniunt in } \\
\text { castra fragore } \\
\text { (Libro VII, vv. 124-126) }\end{array}$ & $\begin{array}{l}\text { qui ve I gran capità dels } \\
\text { romans apelat Massinissa, } \\
\text { ab gran multitud de gents } \\
\text { de peu e de caval; e venien } \\
\text { tots alegres, ab gran brugit } \\
\text { que manaven de si mateys. } \\
\text { (Cap. I) }\end{array}$ \\
\hline $\begin{array}{l}\text { maxime hostis fiducia, } \\
\text { quae non de nihilo profecto } \\
\text { concepta esset, perculsus. } \\
\text { (Liv. XXX, 29) }\end{array}$ & $\begin{array}{l}\text { Omnimus ex visis nil tam } \\
\text { perterruit asprum/ } \\
\text { Hanibalem quam clara } \\
\text { hostis fiducia, magnas/ } \\
\text { Spes animo volventis enim, } \\
\text { nec bella paventia./ } \\
\text { (Libro VII, vv. 127-129) }\end{array}$ & $\begin{array}{l}\text { e no ha res que així espaor- } \\
\text { dís lo tant aspra Aníbal } \\
\text { com fou la gran confianza } \\
\text { de Scipió, enamich seu, e la } \\
\text { esperança de la victoria, } \\
\text { qui no avia tamor poca ni } \\
\text { molta de vanir a la batayla. } \\
\text { (Cap. I) }\end{array}$ \\
\hline
\end{tabular}


Como podemos observar las mayores correspondencias, sobre todo léxicas, se establecen entre Canals y Petrarca. En el primer ejemplo ${ }^{42}$ vemos como el sia amostra$d a$, por la etimología compartida, se corresponde al monstrent de Petrarca y no al visere originario de Livio, quien hace sujeto (eos) a los espías de la oración subordinada.

Observamos como Petrarca, al querer adecuar el mensaje en el metro y componer una obra épica, se permite el añadir información como vemos en Castrorum armorumque genus vultusque virorum/Atque equitum peditumque habitus numerumque manusque/, que sería una ampliación del original qua vellent.

En otras ocasiones, sin embargo, vemos el hecho contrario, ya que el historiador especifica en detalles que Petrarca desecha como cum sex milibus peditum quattuor equitum, Petrarca en cambio dice peditumque equitumque caterve/, sin especificar el número, que el valenciano traduce como gran multitud de gents de peu e de caval.

Otros ejemplos que recogemos son

\begin{tabular}{|c|c|c|}
\hline Tito Livio & Petrarca & Antoni Canals \\
\hline $\begin{array}{l}\text { itaque quamquam et ipse } \\
\text { causa belli erat et aduen- } \\
\text { tu suo turbauerat et pac- } \\
\text { tas indutias et spem foe- } \\
\text { derum, tamen si integer } \\
\text { quam si uictus peteret } \\
\text { pacem aequiora impetrari } \\
\text { posse ratus, nuntium ad } \\
\text { Scipionem misit ut conlo- } \\
\text { quendi secum potestatem } \\
\text { faceret. } \\
\text { (Liv., XXX, 29) }\end{array}$ & $\begin{array}{l}\text { Sive illa egregia morum dul- } \\
\text { cedine tactus, } \\
\text { Seu ventura pavens, seu iam } \\
\text { longissima belli/ } \\
\text { Tedia pertesus, seu fraudem } \\
\text { involvere verbis/ } \\
\text { Insidiasque parans solitasque } \\
\text { recurrere ad artes. } \\
\text { (Libro VII, vv. } 135-138 \text { ) }\end{array}$ & $\begin{array}{l}\text { adés loant-lo dolçament } \\
\text { de les seues grans virtuts } \\
\text { e de l'alta sanch de son } \\
\text { linatge; adés promovent- } \\
\text { lo a pahor per la fortu- } \\
\text { na esdevenidora, que sol } \\
\text { ésser fort duptosa; adés } \\
\text { preposant-li los grans } \\
\text { trebayls e anugs que ha } \\
\text { sostengutz a les grans vic- } \\
\text { tòries que ha sostengudes, } \\
\text { les quals, de present, po- } \\
\text { rien perdre lur fama; adés } \\
\text { mesclant fraus de grans } \\
\text { prometençes ab les dites } \\
\text { paraules; } \\
\text { (Cap. II) }\end{array}$ \\
\hline
\end{tabular}

\footnotetext{
${ }^{42}$ Las palabras en negrita representan las correspondencias léxicas entre los 2 autores medievales.
} 
En este caso observamos incluso, más allá del mensaje que se aleja de la seriedad y del tono político de Tito Livio, un respecto por la estructura de la oración de Petrarca: las conjunciones sive/seu se traducen en Canals como adés... adés y mantiene así el paralelismo exacto, con ciertas añadiduras. Estas son de matiz filosófico como que sol ésser fort duptosa o a veces repetitivas y redundantes, tal como que ha sostengutz a les grans victòries que ha sostengudes.

\begin{tabular}{|c|c|c|}
\hline Tito Livio & Petrarca & Amtonil Ca \\
\hline $\begin{array}{l}\text { Ceterum Scipio, cum } \\
\text { conloquium abnuisset, } \\
\text { ambo ex composito duces } \\
\text { castra protulerunt ut coi- } \\
\text { re ex propinquo possent. } \\
\text { (Liv., XXX, 29) }\end{array}$ & $\begin{array}{l}\text {... Nichil adversatus; et ambo/ } \\
\text { Castra movent ex composito, } \\
\text { multumque propinquis/ } \\
\text { Consedere locis, facilis con- } \\
\text { gressus ubi illos/ } \\
\text { Iungeret. } \\
\text { (Libro VII, vv. 140-144) }\end{array}$ & $\begin{array}{l}\text { Per què cascú mou la sua } \\
\text { host, acostant-se los uns } \\
\text { als altres, he assatjaren-se } \\
\text { en lochs fort prop. } \\
\text { (Cap. II) }\end{array}$ \\
\hline $\begin{array}{l}\text { Ibi in medio locus cons- } \\
\text { pectus undique ne quid } \\
\text { insidiarum esset delec- } \\
\text { tus. } \\
\text { (Liv., XXX, 29) }\end{array}$ & $\begin{array}{l}\text { In medio tumulus legitur cons- } \\
\text { pectus utrimque/ } \\
\text { Detectus situ, nequid inter } \\
\text { frondea claustra” } \\
\text { Antraque silvarum fraudisque } \\
\text { dolique lateret. } \\
\text { (Libro VII, vv. 152-154) }\end{array}$ & $\begin{array}{l}\text { Mas, enmig d'aquestes } \\
\text { dues hosts havia I pug pe- } \\
\text { tit, qui fou esporgat de tots } \\
\text { los arbres que allí eren, en } \\
\text { guia que, cont los capitans } \\
\text { parlarien ensemps, no } s \text { 'i } \\
\text { pogués fer agayt ni trayció } \\
\text { (Cap. II) }\end{array}$ \\
\hline $\begin{array}{l}\text { Hoc quoque ludibrium } \\
\text { casus ediderit fortuna ut } \\
\text { cum patre tuo consule ce- } \\
\text { perim arma. } \\
\text { (Liv., XXX, 30) }\end{array}$ & $\begin{array}{l}\text { Ludibrium quoque Fortune, } \\
\text { que bella parenti/ } \\
\text { Cepta tuo mecum nato clau- } \\
\text { denda reservat,/ } \\
\text { Indigner stupeamne magis? } \\
\text { (Libro VII, vv. 231-233) }\end{array}$ & $\begin{array}{l}\text { ¡O engan manifest de la } \\
\text { fortuna, la qual les bata- } \\
\text { yles que començà lo teu } \\
\text { pare, de qui aguí victòria, } \\
\text { ha reservades a tu, fiyll } \\
\text { seu... Indignar m'e con- } \\
\text { tra tu? } \\
\text { (Cap. V) }\end{array}$ \\
\hline $\begin{array}{l}\text { Sed praeterita magis rep- } \\
\text { rehendi possunt quam } \\
\text { corrigi. } \\
\text { (Liv., XXX, 30) }\end{array}$ & $\begin{array}{l}\text { Culpari transacta tamen licet } \\
\text { usque loquendo/ } \\
\text { Mutari vetitum est } \\
\text { (Libro VII, vv. 245-246) }\end{array}$ & $\begin{array}{l}\text { Mas condició e natura és } \\
\text { de les cozes passades, que } \\
\text { les podem rependre e in- } \\
\text { culpar, no pas corregir ni } \\
\text { mudar. } \\
\text { (Cap. V) }\end{array}$ \\
\hline
\end{tabular}


En el segundo ejemplo podemos observar cómo el escritor valenciano toma como referencia al italiano gracias a la descripción que hace del sitio y el porqué no es apropiado para las emboscadas, datos que no encontramos en el latino.

En el tercero, el elemento revelador es la pregunta explícita que existe en Petrarca y Antoni Canals y que Tito Livio no contiene.

En el cuarto ejemplo ${ }^{43}$, es curioso y revelador el poder observar elementos comunes entre Tito Livio y Canals sin dejar de inspirarse en Petrarca. Vemos por ejemplo les cozes passades que se acercan más por significado al praeterita de Livio que no al transacta (cosas que se han hecho), podem rependre es el reprehendi possunt y corregir es el corrigi del clásico. No obstante, reiterando en su redundancia en la narración, Canals sobrecarga el texto y escribe tanto la versión del paduano como la del florentino. Encontramos así rependre e inculpar que derivan tanto de reprehendi (Livio) como del culpari (Petrarca) y después corregir ni mudar, del texto del historiador corrigi y del renacentista mutari. Es de suponer, pues, que Canals, como ya hemos apuntado, trabajaría con ambos textos, aunque con clara preferencia por el renacentista.

A continuación expondremos otros ejemplos más que reafirman la preferencia por Petrarca a modo de conclusión. ${ }^{44}$

\begin{tabular}{|c|c|c|}
\hline Tito Livio & Petrarca & Antoni Canals \\
\hline $\begin{array}{l}\text { Ita aliena appetivimus } \\
\text { ut de nostris dimicare- } \\
\text { mus. } \\
\text { (Liv., } \mathrm{XXX}, 30)\end{array}$ & $\begin{array}{l}\text {... aliena petebam: } \\
\text { Urgeor in propriis. } \\
\text { (Libro VII, vv. 247-248) }\end{array}$ & $\begin{array}{l}\text { Jo anava cercant açò } \\
\text { d'altri, e are són constret } \\
\text { en açò del meu. } \\
\text { (Cap. V) }\end{array}$ \\
\hline
\end{tabular}

\footnotetext{
${ }^{43}$ Hemos preferido en este caso subrayar los fragmentos que solo coinciden entre el escritor romano y el fraile Antoni Canals.

${ }^{44}$ Trebias no aparece en la versión de Tito Livio, por eso es harto reveladora.
} 


\begin{tabular}{|c|c|c|}
\hline $\begin{array}{l}\text { Quod ego fui ad Trasu- } \\
\text { mennum, ad Cannas, id } \\
\text { tu hodie es } \\
\text { (Liv., XXX, 30) }\end{array}$ & $\begin{array}{l}\text { Qualis apud Cannas, -conce- } \\
\text { de profari-/ } \\
\text { Qualis apud Trebiam! Talem } \\
\text { te suspicor esse./ } \\
\text { (Libro VII, Vv. 258-259) }\end{array}$ & $\begin{array}{l}\text { E si sabies ni.m lexaves } \\
\text { recitar quin fui jo en la } \\
\text { batalla de Trèbias } 44 \text { e en } \\
\text { la de Cannas, tal me pens } \\
\text { que sies tu are. } \\
\text { (Cap. V) }\end{array}$ \\
\hline $\begin{array}{l}\text { Utrimque ferrum, utri- } \\
\text { mque corpora humana } \\
\text { erunt. } \\
\text { (Liv., XXX, 30) }\end{array}$ & $\begin{array}{l}\text {...Michi crede, aderunt, nisi } \\
\text { sistimus iras,/ } \\
\text { Corpora, ferrum, animi vul- } \\
\text { tusque manusque virorum/ } \\
\text { (Libro VII, vv. 268-269) }\end{array}$ & $\begin{array}{l}\text { Creu a mi, Sipió, que si } \\
\text { are no refrenam les nos- } \\
\text { tres ires, que cascuna } \\
\text { part de la batayla haurà } \\
\text { cossos, armes, coratges, } \\
\text { mans he sgarts terribles } \\
\text { de homes. } \\
\text { (Cap. V) }\end{array}$ \\
\hline $\begin{array}{l}\text { haud negauerim prop- } \\
\text { ter non nimis sincere } \\
\text { petitam aut exspec- } \\
\text { tatam nuper pacem } \\
\text { suspectam esse uobis } \\
\text { Punicam fidem: mul- } \\
\text { tum per quos petita sit } \\
\text { ad fidem tuendae pacis } \\
\text { pertinet } \\
\text { (Liv., XXX, 30) }\end{array}$ & $\begin{array}{l}\text { At fuerit suspecta tibi iam fed- } \\
\text { ere fracto/ } \\
\text { Punica forte fides. Sed tu de- } \\
\text { siste vereri/ } \\
\text { Tempus pacis adest. } \\
\text { (Libro VII, vv. 333-335) }\end{array}$ & $\begin{array}{l}\text { Per ventura, Sipió, a tu } \\
\text { serà duptosa la pau dels } \\
\text { de Cartayna, per tal com } \\
\text { te han trenchade la fe. } \\
\text { Mas ja per axò no temes, } \\
\text { car lo temps de pau no } \\
\text { era vengut encara, qui are } \\
\text { és prehent; } \\
\text { (Cap. V) }\end{array}$ \\
\hline $\begin{array}{l}\text { et quemadmodum quia } \\
\text { a me bellum coeptum } \\
\text { est ne quem eius pae- } \\
\text { niteret quoad ipsi inui- } \\
\text { dere di praestiti, ita ad- } \\
\text { nitar ne quem pacis per } \\
\text { me partae paeniteat. } \\
\text { (Liv., XXX, 30) }\end{array}$ & $\begin{array}{l}\text {... Equidem, quia bella moven- } \\
\text { di/ } \\
\text { Auctor eram, donec vetuerunt } \\
\text { Fata, tetendi/ } \\
\text { Ut faustus foret eventos. Sic } \\
\text { federa certe/ } \\
\text { Consilio firmata meo pacem- } \\
\text { que tuebor: } \\
\text { (Libro VII, vv. 345-348) }\end{array}$ & $\begin{array}{l}\text { Qui fuy lo primer en mou- } \\
\text { ra la guerra a les bata- } \\
\text { yles, fins que·ls fats m'o } \\
\text { han vedat, per tal que la } \\
\text { fin sia de pau gloriosa. } \\
\text { E certes, dich que la dita } \\
\text { pau, que serà fermada } \\
\text { per conseyl meu, tendré } \\
\text { leyalment e ferma. } \\
\text { (Cap. V) }\end{array}$ \\
\hline
\end{tabular}


et tunc Mamertinorum sociorum periculum et nunc Sagunti excidium nobis pia ac iusta induerunt arma. (Liv. XXX, 31)
Sera nimis miseris quoniam Romana fuerunt/ Auxilia, atque ingens infamia nostra Saguntum est./ (Libro VII, vv. 393-394) ...foren miserables sol per tal com fort tart hagueren lo socors e ajuda dels romans. Bé bé que gran infamia és nostra, lo fet de la ciutat de Segunt (Cap. VI)

\begin{tabular}{|c|c|c|}
\hline Tito Livio & Petrarca & Antoni Canals \\
\hline $\begin{array}{l}\text { et humanae infirmitatis } \\
\text { memini et uim fortunae } \\
\text { reputo et omnia quaecum- } \\
\text { que agimus subiecta esse } \\
\text { mille casibus scio } \\
\text { (Liv., XXX, 31) }\end{array}$ & $\begin{array}{l}\text { Nec pudet! Et quantis sese } \\
\text { Fortuna revolvat/ } \\
\text { Casibus admoneor, quam } \\
\text { sit via lubrica magne/ } \\
\text { Fortune;... } \\
\text { (Libro VII, vv. 408-410) }\end{array}$ & $\begin{array}{l}\text { Sàpies, Aníbal, que no·m } \\
\text { dóna vergonya considerar } \\
\text { la fortuna en quants casos } \\
\text { se gira e·s regirá. Has-me } \\
\text { amonestar en quina forma } \\
\text { la carrera de la gran for- } \\
\text { tuna és molt alenegoza e } \\
\text { periyllosa; } \\
\text { (Cap. VI) }\end{array}$ \\
\hline $\begin{array}{l}\text { ceterum quemadmodum } \\
\text { superbe et uiolenter me } \\
\text { faterer facere si prius- } \\
\text { quam in Africam traie- } \\
\text { cissem te tua uoluntate } \\
\text { cedentem Italia et impo- } \\
\text { sito in naues exercitu ip- } \\
\text { sum uenientem ad pacem } \\
\text { petendam aspernarer, sic } \\
\text { nunc cum prope manu } \\
\text { conserta restitantem ac } \\
\text { tergiuersantem in Africam } \\
\text { attraxerim nulla sum tibi } \\
\text { uerecundia obstrictus } \\
\text { (Liv., XXX, 31) }\end{array}$ & $\begin{array}{l}\text {.. Nunc cum prope victus } \\
\text { et omni/ } \\
\text { Pulsus ab Italia metuens- } \\
\text { que et velle subactus/ } \\
\text { Pacem ores, poterat recta } \\
\text { cum fronte negari/ } \\
\text { (Libro VII, vv. } 432-434 \text { ) }\end{array}$ & $\begin{array}{l}\text { Mes ara, com te veus prop } \\
\text { de ésser vençut foragitat de } \\
\text { tota Itàlia, demanes la dita } \\
\text { pau més per pahor que per } \\
\text { amor: ab dret front te pot } \\
\text { ésser denegada. } \\
\text { (Cap. VI) }\end{array}$ \\
\hline
\end{tabular}




\begin{tabular}{|c|c|c|}
\hline $\begin{array}{l}\text { sin illa quoque grauia } \\
\text { uidentur, bellum parate } \\
\text { quoniam pacem pati non } \\
\text { potuistis. } \\
\text { (Liv., XXX, 31) }\end{array}$ & $\begin{array}{l}\text {... Quod si nimis illa viden- } \\
\text { tur/ } \\
\text { Importuna animis, gladios } \\
\text { atque arma parate,/ } \\
\text { Indóciles tolerare togam } \\
\text { pacemque perosi./ } \\
\text { (Libro VII, vv. 446-448) }\end{array}$ & $\begin{array}{l}\text { E si per ventura aquestes } \\
\text { coses te semblen massa } \\
\text { importunes, apareylats } \\
\text { les armes e.ls coltells, e no } \\
\text { parlem pus de fer pau. } \\
\text { (Cap. VI) }\end{array}$ \\
\hline $\begin{array}{l}\text { Non confertas autem co- } \\
\text { hortes ante sua quam- } \\
\text { que signa instruebat sed } \\
\text { manipulos aliquantum } \\
\text { inter se distantes ut esset } \\
\text { spatium qua elephanti } \\
\text { hostium acti nihil ordines } \\
\text { turbarent. Laelium, [...] } \\
\text { cum Italico equitatuabsi- } \\
\text { nistro cornu, Masinissam } \\
\text { Numidasque ab dextro } \\
\text { opposuit. } \\
\text { (Liv, XXX, 33) }\end{array}$ & $\begin{array}{l}\text { Scipio distinctam campis } \\
\text { inducit apertis/ } \\
\text { Ordinibus miris aciem, } \\
\text { dextrumque gubernat/ } \\
\text { Massinissa latus Numidis } \\
\text { instructus, et illum/ } \\
\text { Hispanus sublimat equus } \\
\text { cristataque signat/ } \\
\text { Cassis et adverso sinuatur } \\
\text { purpura vento./ } \\
\text { Lelius at levum moderatur } \\
\text { in agmine cornu,/ } \\
\text { Quem sequitur Latiis equi- } \\
\text { tatus ductus ab oris./ } \\
\text { (Libro VII, vv. 740-746) }\end{array}$ & $\begin{array}{l}\text { Scipió ordona son camp } \\
\text { de batayla, la qual posa } \\
\text { abtament e distincta en } \\
\text { diverses órdens de atzes } \\
\text { saviament ordenades. Posa } \\
\text { en lo costat dret Massi- } \\
\text { nissa, qui fou instruit en } \\
\text { Numídia; fa'l montar so- } \\
\text { bra cavals espanyols, ab } \\
\text { totz los de la sua atz; fa'ls } \\
\text { portar baçinetz, qui són di- } \\
\text { visats de cresta. Lo costat } \\
\text { sinistra comena a Lèlio, } \\
\text { sobravestit de porpra. }{ }^{45} \\
\text { (Cap. VII) }\end{array}$ \\
\hline
\end{tabular}

\begin{tabular}{|l|l|l|}
\hline \multicolumn{1}{|c|}{ Tito Livio } & \multicolumn{1}{|c|}{ Petrarca } & \multicolumn{1}{c|}{ Antoni Canals } \\
\hline $\begin{array}{l}\text { quod neque non petere } \\
\text { pacem propter metum } \\
\text { neque manere in ea prae }\end{array}$ & $\begin{array}{l}\text { Hoc metuit. Pacem quotiens } \\
\text { petiere pavore/ }\end{array}$ & $\begin{array}{l}\text { Açò ha temut el cascu- } \\
\text { na vegada que ha dema- } \\
\text { insita animis perfidia po- } \\
\text { tuissent }\end{array}$ \\
(Libro VII, Vv. 806-807) & $\begin{array}{l}\text { nada la pau per pahor, } \\
\text { rompent-la ab sos engans } \\
\text { astuciosos. } \\
\text { (Cap. VIII) }\end{array}$ \\
\hline
\end{tabular}

\footnotetext{
${ }^{45}$ Traducción muy libre y en cierto punto errónea en cuanto a interpretación de la obra de Petrarca: Lelio no era el vestido con púrpura, sino Masinisa y éste último no es que fuera "instruit en Numídia”, sino más bien que comandaba a los Numidas (Numidis instructus).
} 


\begin{tabular}{|c|c|c|}
\hline $\begin{array}{l}\text { Non confertas autem co- } \\
\text { hortes ante sua quamque } \\
\text { signa instruebat sed ma- } \\
\text { nipulos aliquantum inter } \\
\text { se distantes ut esset spa- } \\
\text { tium qua elephanti hos- } \\
\text { tium acti nihil ordines } \\
\text { turbarent } \\
\text { (Liv., XXX, 33) }\end{array}$ & $\begin{array}{l}\text { Instruit ingentes acies; cun- } \\
\text { tosque elephantos,/ } \\
\text { Ut grege monstrifico turba- } \\
\text { tum territet hostem,/ } \\
\text { (Libro VII, Vv. } 840-841 \text { ) }\end{array}$ & $\begin{array}{l}\text { Ordona azes molt grans. } \\
\text { Posa en lo primer front } \\
\text { de la batayla tots los ele- } \\
\text { fants, per ço que ab cruels } \\
\text { speventables bèsties stra- } \\
\text { moscha son anamich. } \\
\text { (Cap. IX) }\end{array}$ \\
\hline $\begin{array}{l}\text { Carthaginiensibus moe- } \\
\text { nia patriae, di penates, } \\
\text { sepulcra maiorum, liberi } \\
\text { cum parentibus coniug- } \\
\text { esque pauidae, aut ex- } \\
\text { cidium seruitiumque aut } \\
\text { imperium orbis terra- } \\
\text { rum, nihil aut in metum } \\
\text { aut in spem medium, os- } \\
\text { tentatur. } \\
\text { (Liv., XXX, 33) }\end{array}$ & $\begin{array}{l}\text { Uxores vobis dulcesque oc- } \\
\text { currere natos/ } \\
\text { Deprecor et trepidas matres } \\
\text { sacramque parentum/ } \\
\text { Canitiem, et patrii curam su- } \\
\text { peresse sepulcri/ } \\
\text { (Libro VII, vv. 913-915) }\end{array}$ & $\begin{array}{l}\text { Soccorretz, donchs, e axits } \\
\text { a carrera a vostres dolçes } \\
\text { muylers, als fiylls, e a les } \\
\text { mares e dones veyles totes } \\
\text { tremoloses, e a les canes } \\
\text { blanques de vostres pares, } \\
\text { la salut dels quals en les } \\
\text { vostres vigorozes armes. } \\
\text { (Cap. X) }\end{array}$ \\
\hline
\end{tabular}

Cierto es que el mensaje no varía mucho entre los tres autores, pues todos están narrando los mismos hechos, pero la diferencia la marca la estructura y la elección de un léxico etimológicamente más afín a la versión de Petrarca, además de las añadiduras descriptivas incorporadas en el italiano y conservadas en el valenciano.

Queda demostrado ya como la historia de Tito Livio ha sido una fuente de inspiración, tanto de forma directa como en el caso de Petrarca, quien se propuso el construir una epopeya de cariz nacionalista con el tema que le otorgaba su ya bien estudiado y trabajado, como de forma indirecta, como en el caso de fra Antoni Canal quien romancea el texto de Petrarca, sobre todo, con una buena base de los clásicos y de Tito Livio como se puede observar en su traducción de Valerio Máximo. 